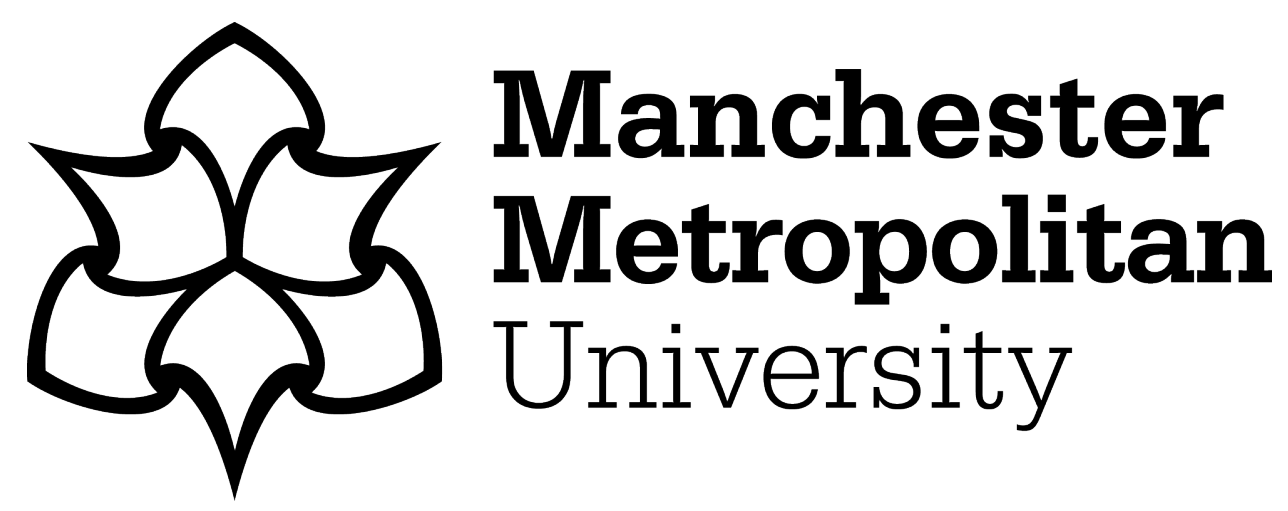

Phibbs, P, Jones, B, Roe, G, Read, D ORCID logoORCID: https://orcid.org/0000-0001-6367-0261, Darrall-Jones, J, Weakley, J, Rock, A and Till, K (2018) The organised chaos of English adolescent rugby union; Influence of weekly match frequency on the variability of match and training loads. European Journal of Sport Science, 18 (3). pp. 341-348. ISSN 1536-7290

Downloaded from: https://e-space.mmu.ac.uk/625777/

Version: Accepted Version

Publisher: Taylor \& Francis

DOI: https://doi.org/10.1080/17461391.2017.1418026

Please cite the published version 


\title{
The organised chaos of English adolescent rugby union; Influence of weekly match frequency on the variability of match and training loads.
}

\begin{abstract}
The aims of this study were to determine the variability of weekly match and training loads in adolescent rugby union players across a competitive season, and to investigate the effect of match frequency on load distribution across different activities. Internal match and training load data (i.e., session-rating of perceived exertion: sRPE) were collected daily from 20 players from a regional academy across a 14-week season. Data were analysed using a mixed-effects linear model, and variability was reported as a coefficient of variation (CV). Differences between 0-, 1-, 2-, and 3-match weeks were assessed using Cohen's $d$ effect sizes and magnitude-based inferences. Mean weekly total match and training sRPE load was 1425 \pm 545 arbitrary units (AU), with a between-player CV of $10 \pm 6 \%$ and within-player CV of 37 $\pm 3 \%$. Mean week-to-week change in total sRPE load was $497 \pm 423$ AU (35\%), and $40 \%$ of weekly observations were outside of the suggested acute:chronic workload ratio 'safe zone'. Total weekly sRPE loads increased substantially with match frequency $(1210 \pm 571 \mathrm{AU}, 1511$ \pm 489 , and $1692 \pm 517 \mathrm{AU}$, for 0-, 1-, and 2-match weeks, respectively), except for 3-match weeks $(1520 \pm 442 \mathrm{AU})$. Weekly match and training loads were highly variable for adolescent rugby players during the competitive season, and match frequency has a substantial effect on the distribution of loads. Therefore, match and training loads should be coordinated, monitored, and managed on an individual basis to protect players from negative training consequences, and to promote long term athlete development.
\end{abstract}

Keywords: Youth, team sport, training, management 


\section{Introduction}

The aim of any well-structured exercise programme is to maximise positive training outcomes (i.e., fitness improvements) and to minimise negative consequences (i.e., fatigue, injury, and overtraining) (Smith, 2003). Training outcomes are determined by the relative response of an athlete (i.e., internal load) to an applied training stimulus (i.e., external load) (Borresen \& Lambert, 2009). Therefore, training loads should be monitored and managed on an individual basis. Both insufficient and excessive match and training loads have been previously shown to increase injury risk and decrease performance in athletes (Cross, Williams, Trewartha, Kemp, \& Stokes, 2016; Gabbett, 2016; Stares et al., 2017). A recent review has suggested that athletes should train hard and smart, as high training loads are required to develop physical qualities but, due to the concurrent increase in injury risk, athletes should be smart in how these loads are accumulated (Gabbett, 2016). In late specialisation sports, the monitoring and management of match and training loads can be difficult due to athletes participating with multiple teams or clubs supervised by various coaches simultaneously (Phibbs, Roe, et al., 2017). As such, this group may be exposed to high risk, suboptimal match and training loads.

Match and training loads should be planned systematically, coordinated and agreed between all coaching and support staff working with adolescent athletes to maximise development and reduce injury risk (Booth, Orr, \& Cobley, 2016; Phibbs, Jones, et al., 2017). Ideally this would be done using a combination of objective and subjective measurement tools (Quarrie et al., 2016). However, expensive objective measures such as global positioning systems, heart rate telemetry, and accelerometers may not be readily available in schools, amateur and professional clubs for practitioners working with adolescent athletes. Subjective measurement tools, such as session-rating of perceived exertion (sRPE), offer a valid and freely accessible measure of global workload that can be used across a variety of training modes 
(Comyns \& Flanagan, 2013; Foster et al., 2001; Phibbs, Roe, et al., 2017). Therefore, training and competition loads can be monitored remotely using sRPE to quantify the accumulation workloads across all training environments.

In adolescent rugby union, elite players have been shown to have a mean weekly sRPE load of 1217 arbitrary units (AU) (Phibbs, Jones, et al., 2017), which is just below the threshold linked to increased injury risk identified in professional senior players during the in-season (1250 AU) (Cross et al., 2016). In adolescent rugby union, weekly training loads (i.e., sRPE, total distance, and PlayerLoad ${ }^{\mathrm{TM}}$ ) have also shown to be highly variable during the competitive phase, with the within-subject coefficient of variation $(\mathrm{CV})$ shown to range from $5-78 \%$ depending on the individual (Phibbs, Jones, et al., 2017). However, these findings were the result of a cross-sectional study and should ideally be investigated using a longitudinal analysis over a longer time period.

It is not just the accumulation of load over a given time which has been linked to increase injury risk, but also the variability of these workloads. The acute:chronic workload ratio (i.e., acute (e.g., 7 day) load in comparison to the chronic load accumulated over a longer period (e.g., 28 day) presented as a ratio) is a metric which should be also considered by coaches and support staff (Gabbett, 2016). The acute:chronic workload ratio has been linked to injury risk in multiple sports (Hulin, Gabbett, Caputi, Lawson, \& Sampson, 2016; Stares et al., 2017; Williams, Trewartha, Cross, Kemp, \& Stokes, 2017), with a lower and upper threshold identified for appropriate loading between 0.8 and 1.3 (Gabbett, 2016). Professional rugby union players have also been shown to have an increased risk of injury with week-toweek changes in training load $>1069$ AU (Cross et al., 2016). Additionally, week-to-week changes in acute training loads $>10 \%$ have been linked to the likelihood of injury in professional rugby league (Gabbett, 2016). 
As previous research in rugby union has focussed on weekly training loads only (Bradley et al., 2015; Cross et al., 2016; Phibbs, Jones, et al., 2017), the effect of match loads on total weekly loads remains unknown. Adolescent rugby union players can participate in up to 3 competitive matches within a weekly microcycle (Hartwig, Naughton, \& Searl, 2008). Therefore, the inclusion of match load data might significantly affect the overall variability of total weekly match and training loads, potentially exposing this cohort to undue negative outcomes. There are currently no data available outlining how match and/or training loads vary across a season in rugby union, or how different weekly match frequencies affect training exposures. Therefore, the aims of the present study were to determine the variability of match and training loads in adolescent rugby union players across a competitive season, and to investigate the effect of match frequency (i.e., 0, 1, 2, and 3 match-weeks) on the distribution of weekly internal loads across different activities. 


\section{Methods}

Participants

Twenty adolescent male rugby union players from a regional academy squad in England (mean $\pm \mathrm{SD}$; age: $17 \pm 1$ years; stature: $182 \pm 6 \mathrm{~cm}$; body mass: $90 \pm 11 \mathrm{~kg}$ ) were recruited for this prospective study. The participants were selected as the highest standard of players in the region, who concurrently participated in school, amateur club, regional academy, and national representative teams. Ethics approval was granted by the University research ethics committee, and all participants and parents provided written informed consent prior to participation in the study. All protocols and procedures were submitted to, and approved by the institutional research ethics committee for testing of human subjects prior to the observational period.

\section{Design}

A prospective cohort design was used to collect player match and training load (i.e., sRPE) data daily over 14 weeks between September and December of the English school rugby season (1960 total observations; 98 observations per participant), with no missing data points. Although English adolescent rugby union players can train year-round, the data collection period was selected to represent the regular English school rugby union (i.e., 15-a-side) competitive season. Weeks were categorised as 0-, 1-, 2-, or 3-match weeks based on the frequency of matches participated in during that week, regardless of duration. There was no minimum duration required for training or match involvements to be included in the analyses, as all involvements would contribute to accumulated weekly loads.

\section{Procedures}


To quantify player training and match loads, sRPE load was calculated from a selfreported online daily match and training load questionnaire (Google Forms, Google, CA, USA), where participants reported information on intensity, duration, and type of all activities undertaken on the previous day. The use of SRPE load was selected due to its ability to be used across all training modes as a measure of global player match and training loads (i.e., physiological and psychological stresses), which has been shown to a reliable and valid measure in rugby union (Comyns \& Flanagan, 2013). Intensity was selected from a drop-down menu corresponding with the text descriptors from a modified Borg category ratio-10 scale (Foster et al., 2001). Duration was recorded to the nearest minute, which was subsequently multiplied by the corresponding sRPE weighting to provide sRPE load values (AU) (Foster et al., 2001). Activity types were categorised as rugby matches (school, amateur club, regional academy, and national representative match-play), rugby training (rugby field-based training, individual and group skills training, captain's runs, and match-day warm ups), gym training (resistance training, prehabilitation, and rehabilitation sessions), and other training/activity (field and gym based conditioning, other organised sport/exercise, and recreational exercise/activity). This method of sRPE load collection has been previously shown to have a typical error of the estimate of $4.3 \%$, and considered robust and valid in a similar adolescent population (Phibbs, Roe, et al., 2017).

\section{Statistical analyses}

All data were exported to a customised spreadsheet (Microsoft Excel, Microsoft, Redmond, USA) for calculation of selected variables. Daily questionnaire data were summated to provide weekly player match and training loads, as well as to quantify week-to-week change and acute:chronic workload ratios. All data are presented as mean \pm standard deviation (SD). A mixed effects linear model (SPSS, v.22, IBM Corp, NY, USA), with random intercepts was 
used to estimate the within- and between-player variability. Variability was reported as the CV (\%), with $90 \%$ confidence limits (CL) as markers of uncertainty of the estimate. The smallest worthwhile change was also calculated as 0.2 of the between-player SD, which can be used in combination with the typical error of a test to detect meaningful change in load for practitioners (Batterham \& Hopkins, 2006). To assess the magnitude of between-match frequency differences, Cohen's $d$ effect sizes (ES) were calculated with threshold values set at $<0.2$ (trivial), 0.2-0.6 (small), 0.6-1.2 (moderate), 1.2-2.0 (large) and $\geq 2.0$ (very large) (Hopkins, Marshall, Batterham, \& Hanin, 2009). To assess for practical significance, magnitude-based inference (MBI) analysis was used with the threshold for a change to be considered practically important (the smallest practical difference; SPD) set at $0.2 \mathrm{x}$ between subject SD, based on Cohen's $d$ ES principle (Hopkins et al., 2009). The probability that the magnitude of difference was greater than the SPD was rated as 25-75\%, possibly; 75-95\%, likely; 95-99.5\%, very likely; $>99.5 \%$, almost certainly (Hopkins et al., 2009). Where the $90 \%$ confidence interval (CI) crossed both the upper and lower boundaries of the $\operatorname{SPD}(\mathrm{ES} \pm 0.2)$, the magnitude of difference was described as unclear (Hopkins et al., 2009). 


\section{Results}

Table I presents the mean $\pm \mathrm{SD}$, within- and between-player CVs $( \pm 90 \% \mathrm{CL})$, and smallest worthwhile change for weekly training and match volumes and sRPE loads. Mean week-to-week change for match and training sRPE loads were $497 \pm 423$ AU (35\%) for total match and training load, $265 \pm 218 \mathrm{AU}(101 \%)$ for rugby matches, $432 \pm 378 \mathrm{AU}(65 \%)$ for rugby training, $232 \pm 214 \mathrm{AU}(61 \%)$ for gym training, and $131 \pm 186 \mathrm{AU}(109 \%)$ for other activity. Mean week-to-week change for weekly match and training volumes were $118 \pm 101$ $\min (34 \%)$ for total match and training volume, $46 \pm 39 \min (92 \%)$ for rugby matches, $110 \pm$ $95 \min (62 \%)$ for rugby training, $48 \pm 49 \min (56 \%)$ for gym training, $38 \pm 68 \min (106 \%)$ for other activity.

\section{***PLEASE INSERT TABLE I NEAR HERE***}

Figure 1 presents the acute:chronic workload ratios across the 14-week season. Of the 280 observations, 74 (26\%) were below the lower threshold (i.e., 0.8$), 169$ (60\%) were within the suggested "safe" zone (i.e., 0.8-1.3), and 37 (13\%) were above the upper threshold (i.e., 1.3) for acute:chronic workload ratios (Gabbett, 2016). No participants remained in the 'safe zone' throughout the observational period.

\section{***PLEASE INSERT FIGURE 1 NEAR HERE*** ***PLEASE INSERT FIGURE 2 NEAR HERE***}

Figure 2 presents the internal training load distribution during 0-, 1-, 2-, and 3-match weeks. Of the 280 observations, 98 (35\%) were during 0-match weeks, 149 (53\%) were during 1-match weeks, $30(11 \%)$ were during 2-match weeks, and $3(1 \%)$ were during 3-match weeks. Table II presents the mean \pm SD, Cohen's $d$ effect sizes ( $\pm 90 \%$ CL), and magnitude-based inferences for weekly training and match sRPE loads by match frequency.

\footnotetext{
***PLEASE INSERT TABLE II NEAR HERE***
} 


\section{Discussion}

This is the first study to analyse the variability of weekly match and training loads across a season in rugby union players. The main finding of the present study was that weekly match and training loads are highly variable in adolescent rugby union players, indicating that their participation in youth rugby union is generally chaotic. As weekly match frequencies increase, gym training and other activity loads are reduced to compensate for the additional match load. However, counter-intuitively, rugby training loads actually increase with match frequency (except for 3-match weeks), which suggests that training exposures may be focussed more towards match-day preparation rather than long term athletic development.

Mean weekly total sRPE load was $1425 \pm 545$ AU (Table I), which is higher than previously reported in English adolescent rugby union players (1217 $\pm 364 \mathrm{AU})$, as match loads were also included in the present study unlike previous research (Phibbs, Jones, et al., 2017). Total sRPE load within-player variability $(\mathrm{CV}=37 \%)$ was greater than the between-player variability $(\mathrm{CV}=10 \%)$, which was also found in all individual activity categories. This finding highlights that weekly training loads of adolescent rugby union players vary more week-toweek for the same player, than they do between players.

Match sRPE loads (263 \pm 255 AU) had a within-player CV of $96 \%$, highlighting the potential challenges with the competitive schedule in English adolescent rugby union. The same adolescent rugby player can play up to three games one week, and have no games in the next week during the competitive phase of the season (Hartwig et al., 2008). Perceptual wellbeing, lower-body neuromuscular function and creatine kinase concentration have been shown to remain elevated up to 72 hours post-match in academy rugby union players (Roe et al., 2016). Excessive training or match-play during this time period could compound the fatigue response, which could lead to illness, injury, overtraining, and reduced performance (Cunniffe et al., 2010; DiFiori et al., 2014; Johnston, Gabbett, \& Jenkins, 2013). Additionally, as 
participation in rugby union matches has a substantially higher injury occurrence than training in academy rugby union players (47 vs. 1.4 per 1000 hours) (Palmer-Green et al., 2013, 2015), the organisation of competitive matches should be planned appropriately to prevent congested periods of multiple fixtures within a short space of time due to the elevated injury risk (Tee, Lebatie, Till, \& Jones, 2017).

Rugby-specific training sRPE loads $(662 \pm 465$ AU) had a lower within-player variability than match loads, however they still had a substantial CV of $66 \%$. As training sessions are generally planned around match schedules, the high variability of matches in this population will have a significant knock-on effect on training schedules, and consequent exposures. If long-term athletic development is the primary focus of a programme, wellplanned training exposures should be prioritised to develop physical, technical and tactical skills and qualities (DiFiori et al., 2014; Llyod et al., 2016; Smith, 2003). In contrast, if match exposures are prioritised, players will be placed at a greater risk of injury, with increased fatigue due to excessive exposure to the maximum physiological and psychological demands of competition (Palmer-Green et al., 2013, 2015; Smith, 2003).

Gym training sRPE loads (379 \pm 269 AU) had a similar within-player variability to rugby-specific training with a $\mathrm{CV}$ of $62 \%$. This may also be influenced by the inconsistent match schedule, as strength sessions need to be programmed around fixtures to allow recovery from matches before strength training, and also to allow sufficient recovery post-training before matches (Roe et al., 2016; Soares et al., 2015). Other activity (120 \pm 195 AU) was the most highly variable sRPE load category with a within-player CV of $138 \%$ and a betweenplayer $\mathrm{CV}$ of $88 \%$. Although rugby union is considered a late-specialisation sport, academy players at the under-18 age category in this study did not participate in much other sporting activities other than rugby during the competitive phase of the season (including general onor off-feet conditioning, other organised sport, or recreational physical activity). The 
participation of adolescent rugby union players in other sports and activities outside of the rugby union season was beyond the scope of the present study, but may be an area of consideration for future research.

Total weekly match and training volume was $349 \pm 128 \mathrm{~min}$ (Table I), which is similar to previous findings in English adolescent rugby union players (301 $\pm 92 \mathrm{~min})$, when match duration is excluded (50 $\pm 44 \mathrm{~min})$ (Phibbs, Jones, et al., 2017). Total training volume withinplayer variability $(\mathrm{CV}=34 \%)$ was also greater than the between-player variability $(\mathrm{CV}=14 \%)$. The variability of match and training volumes were similar to the variability of sRPE loads for all activity categories, which suggests that it is not simply an increase or decrease in either training time or intensity in isolation that differs from week-to-week in adolescent rugby union players, but a variance in both concurrently. As the variability of total weekly match and training volumes closely reflects the variability of total weekly sRPE loads, the monitoring of training volumes alone may offer a simpler alternative as a minimum standard for match and training load accumulation for those with limited resources to collect volume and intensity data concurrently. However, it should be noted that for a comprehensive analysis of match and training load accumulation, ideally a combination of internal and external load measures should be used (Quarrie et al., 2016).

Mean week-to-week change in total weekly match and training sRPE loads was $35 \%$ (497 $\pm 423 \mathrm{AU})$, and even higher for individual activity categories (61-109\%). The absolute week-to-week change is lower than the value previously linked to increased injury risk in senior professional players (1069 AU). However, it should be noted that adolescent rugby union players have been shown to have lower absolute weekly sRPE loads than senior professional players (Phibbs, Jones, et al., 2017). As relative week-to-week changes in training loads of $>10 \%$ have also been linked to a greater likelihood of injury in rugby players, coaches and support staff should aim to reduce the substantial relative change (i.e., 35\%) in match and 
training exposures of adolescent rugby union players (Gabbett, 2016). This could be achieved by simply increasing rugby-specific training loads during periods of low match demands, and decreasing training loads during periods of high match demands.

In addition to significant week-to-week changes, $40 \%$ of adolescent rugby union players' weekly match and training loads fell outside of the suggested 'safe zone' range of 0.81.3, placing them at higher risk of injury (Gabbett, 2016). Additionally, no participants remained within the 'safe zone' throughout the observational period. The substantial variability of weekly match and training loads shown in the present study may be hazardous to adolescent rugby union players, as both high and low acute:chronic workload ratios have been related to increased injury risk, which may remain elevated for up to 28 days (Cross et al., 2016; Stares et al., 2017). Although it may seem beneficial for players to be more frequently below the appropriate zone than above, this is not accurate as low load weeks will leave players underprepared for competition and could predispose players to significant spikes in match and training loads in the following weeks. Furthermore, from a long term athletic development perspective, low training loads may also provide an inadequate stimulus for physical development (Weakley et al., 2017). It should be noted that the suggested 'safe zone' may differ between- and within-populations, and should be investigated specifically with adolescent rugby players in future research. Additionally, the use of exponentially weighted moving averages (EWMA), and the length of different "acute" and "chronic" durations (e.g., 3:21 vs. 7:28 days), should be evaluated in adolescent rugby union players, as these methods may affect the sensitivity of the measures in relation to injury risk (Carey et al., 2016).

The distribution of match and training loads generally followed a logical trend with changes in match frequency. When match frequency increased, gym training and other activity loads were decreased to allow for compensation with increased match loads. However, rugby training loads increased concurrently with match frequency, with the exception of 3-match 
weeks. This suggests that training exposures may be scheduled to focus more on preparing for upcoming matches, rather than to develop physical qualities and technical skills over a longer term. A more appropriate long term athletic development approach would be the reverse (DiFiori et al., 2014; Llyod et al., 2016). Training exposures should be increased during periods of lower match demands to reduce overall variability of match and training loads, develop physical qualities and technical skill, to ultimately reduce injury risk and improve performance. Total weekly match and training loads also increased with match frequency, except for 3-match weeks. Due to the increased fatigue response associated with match-play compared to training, it may be expected that, during weeks with 3 matches within 7 days, overall training loads would be reduced. As match frequency has a substantial effect on the distribution and magnitude of match and training loads, competitive fixtures should be planned appropriately to avoid congested periods (Tee et al., 2017), and conversely, to avoid extended periods with no match exposure at all.

A limitation of the present study is that only subjective match and training load measures were used. Future research should aim to investigate the variability of objective training load measures in adolescent rugby union players (e.g., GPS, accelerometer, or heart rate data), as the use of sRPE as a global measure of load in isolation does not differentiate between the specific psychological, physiological, or biomechanical stresses produced by different activities. However, longitudinal monitoring of objective match and training loads can be highly challenging due to the lack of availability of expensive monitoring tools in this population, compliance issues associated with longitudinal study designs, and potential instrument recording failure. Injury data are also not presented in the current study due to the limited sample size. Future studies with larger sample sizes are required to determine the association between match and training loads and injury occurrence in adolescent rugby union players. 


\section{Conclusion}

The present longitudinal study is the first to examine the variability of weekly match and training loads in rugby union athletes across a season. Findings demonstrate the highly variable nature of training and match exposures during the competitive season in adolescent rugby union players. Adolescent rugby union players may be regularly exposed to high risk of injury due to the large within-player variability of match and training loads (37\%), mean weekto-week change in loads (35\%), and percentage of weeks with an acute:chronic workload ratio outside of the suggested "safe" zone (40\%). Match loads had a within-player CV of $96 \%$ which demonstrates the inconsistent nature of competitive fixtures in English schoolboy rugby union. As training schedules can be generally planned around match fixtures, inconsistent match scheduling will have substantial effect on the variability of accumulated match and training loads. Gym training and other activity loads were reduced when match frequencies increased. However, rugby training loads and match frequency increased concurrently (except for 3match weeks), which should be reversed to allow players to train more when match loads are low, and vice versa. Match and training loads of adolescent rugby union players should therefore be coordinated, monitored, and managed on an individual basis to reduce excessive variability, protect players from unnecessary injury risk, and to ensure players are exposed to an appropriate training stimulus. 


\section{References}

Batterham, A. M., \& Hopkins, W. G. (2006). Making meaningful inferences about magnitudes. International Journal of Sports Physiology and Performance, 1(1), 50-57.

Booth, M., Orr, R., \& Cobley, S. P. (2016). Call for coordinated and systematic training load measurement (and progression) in athlete development: a conceptual model with practical steps. British Journal of Sports Medicine, O(0), bjsports-2016-096358. https://doi.org/10.1136/bjsports-2016-096358

Borresen, J., \& Lambert, M. I. (2009). The Quantification of Training Load, the Training Response and Effect on Performance. Sports Medicine, 39(9), 779-95. https://doi.org/10.2165/11317780-000000000-00000

Bradley, W. J., Cavanagh, B. P., Douglas, W., Donovan, T. F., Twist, C., Morton, J. P., \& Close, G. L. (2015). Energy intake and expenditure assessed "in-season" in an elite European rugby union squad. European Journal of Sport Science, 15(6), 469-479. https://doi.org/http://dx.doi.org/10.1080/17461391.2015.1042528

Carey, D. L., Blanch, P., Ong, K.-L., Crossley, K. M., Crow, J., \& Morris, M. E. (2016). Training loads and injury risk in Australian football—differing acute: chronic workload ratios influence match injury risk. British Journal of Sports Medicine, bjsports-2016096309. https://doi.org/10.1136/bjsports-2016-096309

Comyns, T., \& Flanagan, E. P. (2013). Applications of the session rating of perceived exertion system in professional rugby union. Strength \& Conditioning Journal, 35(6), 78-85. Retrieved from http://journals.1ww.com/nscascj/Abstract/2013/12000/Applications_of_the_Session_Rating_of_Perceived.13.aspx\%5 Cnpapers2://publication/uuid/7001FCA5-47F9-4E60-A94C-334D5B856135

Cross, M. J., Williams, S., Trewartha, G., Kemp, S. P. T., \& Stokes, K. A. (2016). The Influence of In-Season Training Loads on Injury Risk in Professional Rugby Union. 
International Journal of Sports Physiology and Performance, 11(3), 350-355.

https://doi.org/10.1123/ijspp.2015-0187

Cunniffe, B., Hore, A. J., Whitcombe, D. M., Jones, K. P., Baker, J. S., \& Davies, B. (2010). Time course of changes in immuneoendocrine markers following an international rugby game. European Journal of Applied Physiology, 108(1), 113-122. https://doi.org/10.1007/s00421-009-1200-9

DiFiori, J. P., Benjamin, H. J., Brenner, J. S., Gregory, A., Jayanthi, N., Landry, G. L., \& Luke, A. (2014). Overuse injuries and burnout in youth sports: a position statement from the American Medical Society for Sports Medicine. British Journal of Sports Medicine, 48(4), 287-288. https://doi.org/10.1136/bjsports-2013-093299

Foster, C., Florhaug, J., Franklin, J., Gottschall, L., Hrovatin, L., Parker, S., ... Dodge, C. (2001). A new approach to monitoring exercise training. Journal of Strength and Conditioning Research, 15(1), 109-15. https://doi.org/10.1519/15334287(2001)015<0109:ANATME $>2.0 . C O ; 2$

Gabbett, T. J. (2016). The training-injury prevention paradox: should athletes be training smarter and harder? British Journal of Sports Medicine, 1-9. https://doi.org/10.1136/bjsports-2015-095788

Hartwig, T. B., Naughton, G. A., \& Searl, J. (2008). Defining the volume and intensity of sport participation in adolescent rugby union players. International Journal of Sports Physiology and Performance, 3(1), 94-106. https://doi.org/10.1016/S14402440(07)70362-6

Hopkins, W. G., Marshall, S. W., Batterham, A. M., \& Hanin, J. (2009). Progressive statistics for studies in sports medicine and exercise science. Medicine and Science in Sports and Exercise, 41(1), 3-12. https://doi.org/10.1249/MSS.0b013e31818cb278

Hulin, B. T., Gabbett, T. J., Caputi, P., Lawson, D. W., \& Sampson, J. A. (2016). Low 
chronic workload and the acute:chronic workload ratio are more predictive of injury than between-match recovery time: a two-season prospective cohort study in elite rugby league players. British Journal of Sports Medicine, 50(16), 1008-12. https://doi.org/10.1136/bjsports-2015-095364

Johnston, R. D., Gabbett, T. J., \& Jenkins, D. G. (2013). Influence of an intensified competition on fatigue and match performance in junior rugby league players. Journal of Science and Medicine in Sport, 16(5), 460-465. https://doi.org/10.1016/j.jsams.2012.10.009

Llyod, R. S., Cronin, J. B., Faigenbaum, A. D., Haff, G. G., Howard, R., Kraemer, W. J., ... Oliver, J. L. (2016). National strength and conditioning association statement on longterm athletic development. Journal of Strength and Conditioning Research, 30(6), $1491-1509$.

Palmer-Green, D. S., Stokes, K. A., Fuller, C. W., England, M., Kemp, S. P. T., \& Trewartha, G. (2013). Match Injuries in English Youth Academy and Schools Rugby Union. The American Journal of Sports Medicine, 41(4), 749-755.

https://doi.org/10.1177/0363546512473818

Palmer-Green, D. S., Stokes, K. A., Fuller, C. W., England, M., Kemp, S. P. T., \& Trewartha, G. (2015). Training Activities and Injuries in English Youth Academy and Schools Rugby Union. The American Journal of Sports Medicine, 43(2), 475-481. https://doi.org/10.1177/0363546514560337

Phibbs, P. J., Jones, B., Roe, G., Read, D., Darrall-Jones, J., Weakley, J., ... Till, K. (2017). Organised chaos in late specialisation team sports: Weekly training loads of elite adolescent rugby union players. Journal of Strength and Conditioning Research. https://doi.org/10.1519/JSC.0000000000001965

Phibbs, P. J., Roe, G., Jones, B., Read, D., Weakley, J., Darrall-Jones, J., \& Till, K. (2017). 
Validity of daily and weekly self-reported training load measures in adolescent athletes. Journal of Strength and Conditioning Research, 31(4), 1121-1126.

https://doi.org/10.1519/JSC.0000000000001708

Quarrie, K. L., Raftery, M., Blackie, J., Cook, C. J., Fuller, C. W., Gabbett, T. J., ...

Mellalieu, S. D. (2016). Managing player load in professional rugby union: a review of current knowledge and practices. British Journal of Sports Medicine, 0, 1-8. https://doi.org/10.1136/bjsports-2016-096191

Roe, G., Till, K., Phibbs, P. J., Weakley, J., Read, D., \& Jones, B. (2016). Changes in markers of fatigue following a competitive match in elite academy rugby union players. South African Journal of Sports Medicine, 28(1), 2-5. https://doi.org/10.17159/2078$516 X / 2016 / v 28 i 1 \mathrm{a} 418$

Smith, D. J. (2003). A Framework for Understanding the Training Process Leading to Elite Performance. Sports Medicine, 33(15), 1103-1126. https://doi.org/10.2165/00007256200333150-00003

Soares, S., Ferreira-Junoir, J. B., Perreira, M. C., Cleto, V. A., Castanheira, R. P., Cadore, E. L., ... Bottaro, M. (2015). Dissociated time course of muscle damage revovery between single- and multi-joint exercises in highly resistance-trained men. Journal of Strength and Conditioning Research, 2594-2599. https://doi.org/10.1519/JSC.0000000000000899

Stares, J., Dawson, B., Peeling, P., Heasman, J., Rogalski, B., Drew, M., ... Lester, L. (2017). Identifying high risk loading conditions for in-season injury in elite Australian football players. Journal of Science and Medicine in Sport, 6-11. https://doi.org/10.1016/j.jsams.2017.05.012

Tee, J. C., Lebatie, F., Till, K., \& Jones, B. (2017). Injury incidence and characteristics in South African school first team rugby: A case study. South African Journal of Sports 
Medicine, 29, 1-7. https://doi.org/10.17159/2078-516X/2017/v29i0a1532

Weakley, J. J. S., Till, K., Darrall-Jones, J., Roe, G. A. B., Phibbs, P. J., Read, D., \& Jones, B. L. (2017). Strength and Conditioning Practices in Adolescent Rugby Players:

Relationship with Changes in Physical Qualities. Journal of Strength and Conditioning Research. https://doi.org/10.1519/JSC.0000000000001828

Williams, S., Trewartha, G., Cross, M. J., Kemp, S. P. T., \& Stokes, K. A. (2017).

Monitoring What Matters: A Systematic Process for Selecting Training Load Measures. International Journal of Sports Physiology and Performance, 12(S2), 101-106. https://doi.org/10.1123/ijspp.2016-0337 
Table I. Variability of weekly match and training volumes and internal loads of adolescent rugby union players across a season.

\begin{tabular}{cccc} 
& Within- & Between- Player & Smallest \\
Mean \pm SD & Player CV & CV & Worthwhile \\
& $(\% ; \pm 90 \%$ CL $)$ & $(\% ; \pm 90 \%$ CL $)$ & Change (\%) \\
\hline
\end{tabular}

\section{Rugby Match Time \\ (min) \\ Rugby Training Time \\ (min) \\ Gym Training Time \\ (min) \\ Other Activity Time \\ (min)}

Total Time

(min)

Rugby Match Load

(AU)

(AU)

Gym Training Load

(AU)

Other Activity Load

(AU)

$50 \pm 44$
$178 \pm 115$
$86 \pm 61$
$36 \pm 62$

$88 ; \pm 6$

$16 ; \pm 16$

3.2

59; \pm 4

$59 ; \pm 4$

$25 ; \pm 10$

5.0

$40 ; \pm 13$

7.9

$81 ; \pm 28$

16.3

$349 \pm 128$

$34 ; \pm 2$

$14 ; \pm 5$

$263 \pm 255$

$96 ; \pm 7$

$16 ; \pm 18 \%$

$662 \pm 465$

$66 ; \pm 5$

$18 ; \pm 10 \%$

3.5

$379 \pm 269$

$62 ; \pm 4$

$36 ; \pm 12 \%$

$120 \pm 195$

$138 ; \pm 10$

$88 ; \pm 28 \%$

17.5

Total Load

(AU)

$1425 \pm 545$

$37 ; \pm 3$

$10 ; \pm 6 \%$

2.0 
Table II. Differences in weekly match and training loads of adolescent rugby union players by weekly match frequency.

\begin{tabular}{|c|c|c|c|c|c|c|c|c|c|c|}
\hline & \multicolumn{4}{|c|}{ Mean \pm SD } & \multicolumn{6}{|c|}{ Cohen's $d$ Effect Size $\pm 90 \%$ Confidence Intervals and MBI } \\
\hline & $\begin{array}{c}\text { 0-Match } \\
\text { Weeks }\end{array}$ & $\begin{array}{l}\text { 1-Match } \\
\text { Weeks }\end{array}$ & $\begin{array}{c}\text { 2-Match } \\
\text { Weeks }\end{array}$ & $\begin{array}{c}\text { 3-Match } \\
\text { Weeks }\end{array}$ & $\begin{array}{l}\text { 0- vs. 1- } \\
\text { Matches }\end{array}$ & $\begin{array}{l}\text { 0- vs. 2- } \\
\text { Matches }\end{array}$ & $\begin{array}{l}\text { 0- vs. 3- } \\
\text { Matches }\end{array}$ & $\begin{array}{l}\text { 1- vs. 2- } \\
\text { Matches }\end{array}$ & $\begin{array}{l}\text { 1- vs. 3- } \\
\text { Matches }\end{array}$ & $\begin{array}{l}\text { 2- vs. 3- } \\
\text { Matches }\end{array}$ \\
\hline \multicolumn{11}{|l|}{ Rugby Match } \\
\hline \multirow{2}{*}{ Load (AU) } & $0 \pm 0$ & $348 \pm 150$ & $633 \pm 175$ & $973 \pm 474$ & - & - & - & $1.9 \pm 0.4$ & $4.1 \pm 5.3$ & $1.9 \pm 4.5$ \\
\hline & & & & & $* * * *$ & $* * * *$ & $* * * *$ & $* * * *$ & & \\
\hline \multicolumn{11}{|l|}{ Rugby Training } \\
\hline \multirow[t]{2}{*}{ Load (AU) } & $563 \pm 496$ & $713 \pm 413$ & $764 \pm 454$ & $477 \pm 49$ & $0.3 \pm 0.2$ & $0.4 \pm 0.3$ & $-0.2 \pm 0.2$ & $0.1 \pm 0.4$ & $-0.6 \pm 0.2$ & $-0.6 \pm 0.3$ \\
\hline & & & & & $* *$ & $* *$ & $*$ & & $* * * *$ & $* * *$ \\
\hline \multicolumn{11}{|l|}{ Gym Training } \\
\hline \multirow{2}{*}{ Load (AU) } & $494 \pm 308$ & $331 \pm 213$ & $273 \pm 214$ & $70 \pm 62$ & $-0.5 \pm 0.2$ & $-0.7 \pm 0.3$ & $-1.4 \pm 0.3$ & $-0.3 \pm 0.3$ & $-1.2 \pm 0.4$ & $-0.9 \pm 0.5$ \\
\hline & & & & & $* * * *$ & $* * * *$ & $* * * *$ & $*$ & $* * *$ & $* * *$ \\
\hline \multicolumn{11}{|l|}{ Other Activity } \\
\hline \multirow[t]{2}{*}{ Load (AU) } & $153 \pm 227$ & $117 \pm 116$ & $40 \pm 73$ & $0 \pm 0$ & $0.2 \pm 0.2$ & $-0.5 \pm 0.2$ & $-0.9 \pm 0.2$ & $-0.4 \pm 0.2$ & $0.6 \pm 0.1$ & $-0.5 \pm 0.3$ \\
\hline & & & & & & $* *$ & $* * * *$ & $* * *$ & $* * * *$ & $* * *$ \\
\hline \multirow[t]{2}{*}{ Total Load (AU) } & $1210 \pm 571$ & $1511 \pm 489$ & $1692 \pm 517$ & $1520 \pm 442$ & $0.5 \pm 0.2$ & $0.8 \pm 0.3$ & $0.5 \pm 1.3$ & $0.4 \pm 0.3$ & $0.0 \pm 1.5$ & $-0.3 \pm 1.5$ \\
\hline & & & & & $* * * *$ & $* * * *$ & & $* *$ & & \\
\hline
\end{tabular}

MBI = magnitude-based inferences: $*$ possibly, ${ }^{* *}$ likely, ${ }^{* * *}$ very likely, and **** almost certainly. 


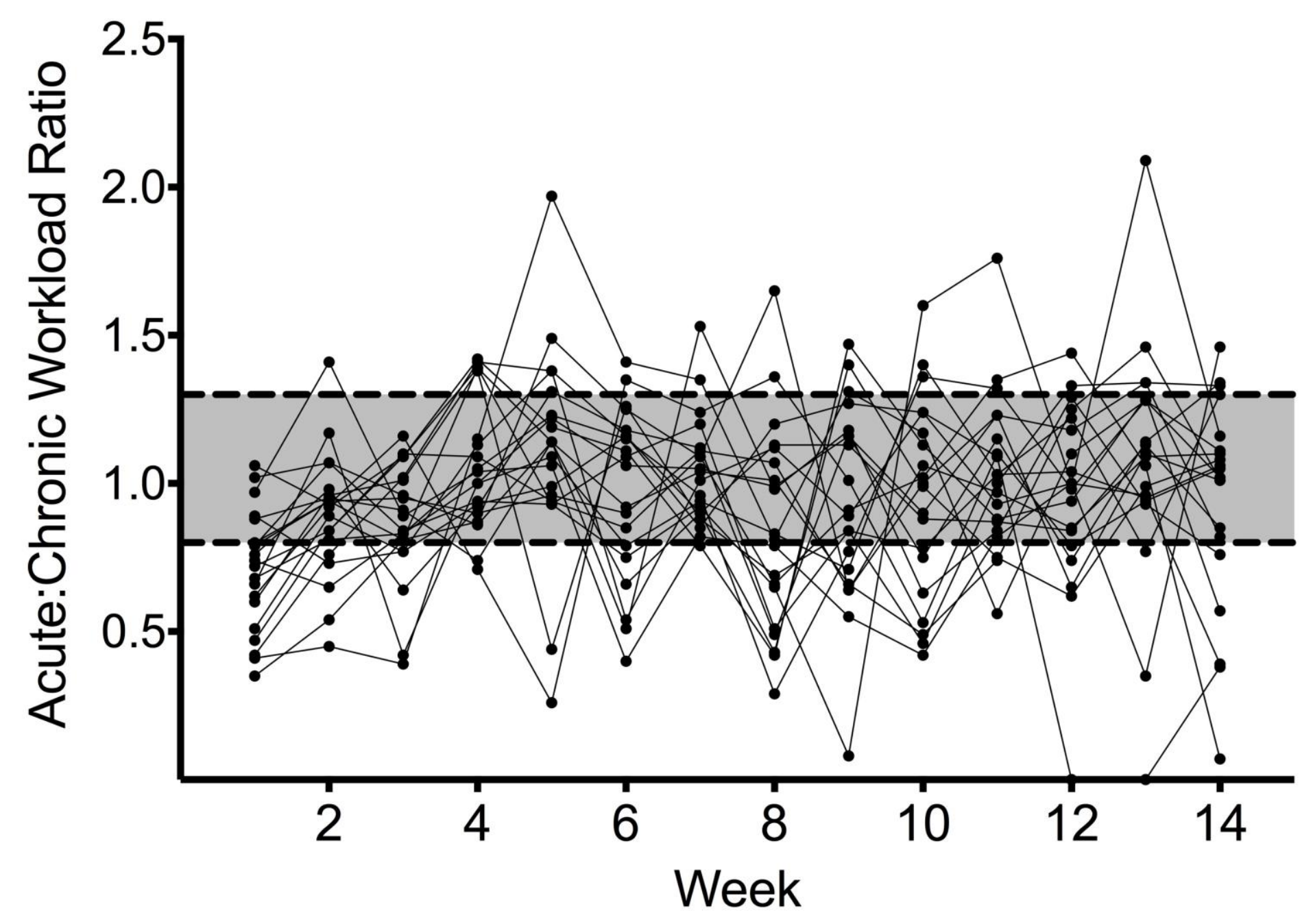

Figure 1: Total SRPE acute:chronic workload ratios across a season in adolescent rugby union players. 


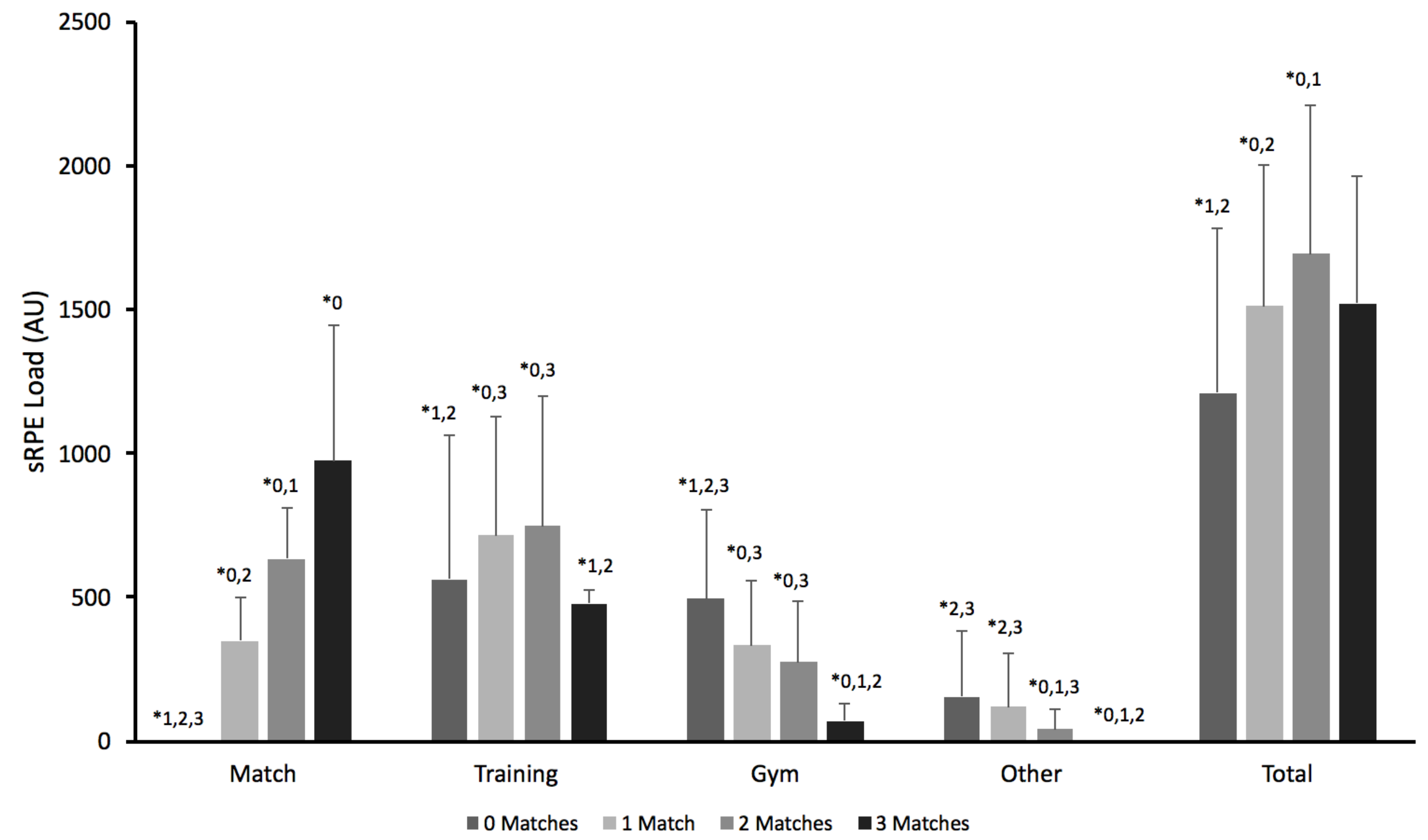

Figure 2: Weekly match and training load distribution of adolescent rugby union players by match frequency. $* 75 \%$ likelihood difference between match weeks: $0=0$ matches, $1=1$ match, $2=2$ matches, and $3=3$ matches. 